\title{
Impact of Infectious Diseases on Cognitive Development in Childhood and Beyond: Potential Mitigational Role of Hygiene
}

\author{
M. Khalid Ijaz and Joseph R. Rubino* \\ Reckitt Benckiser LLC., One Philips Parkway, Montvale, NJ 07645, USA
}

\begin{abstract}
Enteric infections in the early years of childhood can exacerbate underlying malnutrition and, if not addressed, can lead to a vicious and synergistic cycle of malnutrition-enteric infection-malnutrition. Cognitive impairment is a key detrimental outcome associated with this cycle of malnutrition and enteric infection. Mechanistically, diversion of metabolic resources away from the developing brain under conditions of nutritional stress may underlie the impairment of cognitive function. Evidence indicates that the effects of the synergy between malnutrition and enteric pathogens last far beyond the time of infection and can lead to long-term effects on cognition. Indeed, emerging evidence suggests a potential for later-life vulnerability to neurodegenerative diseases as a consequence of enteric infectious diseases on early-life brain development. Simple interventions for improving hygiene have proven to lessen the burden of enteric infectious disease. The mitigational role of good hygiene practices has the potential to break the vicious cycle of malnutrition and enteric infection, and contribute to improving the cognitive development potential of children at risk.
\end{abstract}

Keywords: Diarrhea, cognitive, enteric, hygiene, infection, malnutrition.

\section{INTRODUCTION}

The first five years of life are crucial for a child's cognitive, physical, and emotional development. According to the World Health Organization (WHO), a child's experience during the early years sets a "critical foundation for their entire life course" [1]. It is becoming increasingly evident that infectious diseases experienced in the early years are a significant component of that course.

Malnutrition is associated with an estimated 5.6 million deaths among children every year [2]. However, the burden of malnutrition is reflected not only in an unacceptable level of mortality, but on the associated morbidity and long-term effects on physical, emotional, and cognitive development in survivors of malnutrition [3]. Not only are the effects of malnutrition complex, its causes are as well. A factor that is potentially even more important than lack of food is the presence of repeated or persistent enteric infections, which can result in an inability to absorb what little food is taken in. This can, in turn, lead to a vicious cycle of enteric infections worsening and being worsened by malnutrition [3].

This review examines the vicious cycle of malnutrition and enteric infectious diseases, and how this plays a key role in impairing cognitive development in a child's early years. The role of good hygiene in reducing the burden of enteric infectious diseases and breaking the vicious cycle is discussed, along with practical measures that may serve to interrupt pathogen transmission in children, thereby improving their chance to achieve their full development potential.

Address correspondence to this author at the Reckitt Benckiser LLC., One Philips Parkway, Montvale, NJ 07645, USA; Tel: +1-201-573-6083; Fax: +1-201-573-6046; E-mail: Joseph.Rubino@rb.com

\section{THE VICIOUS CYCLE - A SYNERGISTIC INTERACTION BETWEEN MALNUTRITION AND ENTERIC INFECTION}

Globally, infectious diarrhea in childhood remains one of the leading causes of morbidity and mortality. It is estimated that 1.9 million children die every year from infectious diarrhea - equating to more than 5000 each day [2]. Unhygienic, unsanitary living conditions are central to these alarming statistics. In 2005, it was estimated that 1.1 billion ( $17 \%$ of the global population) and 2.6 billion ( $42 \%$ of the global population) did not have access to safe water and safe sanitation, respectively - these proportions are projected to increase to respective levels of 2.9 billion and 4.2 billion by 2025 [3]. Compounding this, 2.6 billion lack even pit latrines ( $42 \%$ of the global population, projected to be 4.2 billion by 2025) [3].

Diarrheal illness is associated with a range of enteric pathogens (Table 1), with rotavirus and Vibrio cholerae particularly prevalent causes of acute diarrhea in children aged 5 years of age or less [4-8]. In contrast to most bacterial and viral enteric pathogens, intestinal parasites are associated with chronic enteric infection. A recent analysis of populations at risk of soil-transmitted helminth transmission found that, globally in 2010, an estimated 5.3 billion people, including 1.0 billion school-aged children, lived in areas stable for transmission of at least one species, with $69 \%$ of these individuals living in Asia. A further 143 million (31.1 million school-aged children) lived in areas of unstable transmission for at least one species [9].

A substantial proportion of global malnutrition is due to impaired intestinal absorptive function resulting from multiple and repeated enteric infections (caused by acute as well as persistent infections) [3]. Repeated bouts of enteric 
Table 1. Enteric Pathogens Implicated in Diarrheal Illness

\begin{tabular}{|c|c|}
\hline Viruses & Bacteria \\
\hline \hline Rotaviruses & Enteropathogenic E. coli \\
Noroviruses & Enteroaggregative E. coli \\
Adenoviruses & Shigella dysenteriae \\
Astroviruses & Salmonella typhi \\
Bocaviruses & Vibrio cholerae \\
Toroviruses & Campylobacter jejuni \\
Coronaviruses & Staphylococcus aureus \\
& Yersinia enterocolitica \\
& Clostridium difficile \\
\hline Protozoa & Helminths (Worms) \\
\hline \hline Giardia lamblia & Ascaris lumbricoides \\
Entamoeba histolytica & Enterobius vermicularis \\
Cryptosporidium parvum & Trichuris trichiura \\
Cyclospora cayetanensis & Taenia saginata \\
& Hookworms (Ancylostoma duodenale \\
& \& Necator americanus) \\
\hline
\end{tabular}

infections lead to intestinal injury and, consequently, nutrient malabsorption during the developmentally-critical first 2 years of childhood. This can result in detrimental effects on both growth and cognitive development that extend long beyond the infection [3, 10]. Both symptomatic and asymptomatic infections have been implicated in the establishment of this vicious cycle of synergistic malnutrition-enteric pathogen-malnutrition (Fig. 1) [11]. Such is the impact of this cycle that an international research team - Malnutrition and Enteric Disease Research (MALED) - was established in 2009. This five-year, multi-center project, funded by a $\$ 30$ million grant from the Bill and Melinda Gates Foundation will specifically investigate the relationship between malnutrition and intestinal infections and the consequences of these conditions on various aspects of child development [12].

Challenges in addressing enteric pathogens include the emergence of multidrug-resistant strains of bacteria [13-15] and the changing pattern of enteroaggregative $E$. coli (EAEC), which historically was associated with a selflimiting diarrheal illness in travelers to tropical areas, but now is increasingly associated with persistent diarrheal illness in young children in developing countries [16, 17]. Furthermore, although chemotherapy is an effective tool for the strategic control of enteric parasitic infections as a shortterm goal, chemotherapeutic intervention alone has been found to bear no significant long-term impact [18]. For example, in a study conducted in a slum in Visakhapatnam, South India, Ascaris lumbricoides re-infection prevalence following treatment with albendazole exceeded the preintervention level over the subsequent nine month period [19].

\section{ENTERIC INFECTIOUS DISEASES AND IMPAIRED COGNITIVE DEVELOPMENT}

Malnutrition and enteric infections during the first two years of life are implicated in impaired cognitive abilities in later life. In one longitudinal study, 239 Peruvian children were followed from birth to 2 years for anthropometrics, stool samples, and diarrheal status [20]. At 9 years of age, cognitive function was assessed in 143 children using the Wechsler Intelligence Scale for Children - Revised (WISCR). After adjustment for socioeconomic, schooling and other significant factors, malnutrition and Giardia lamblia infection in early childhood had a strong adverse effect on cognitive function (Fig. 2).

A separate study assessed the long-term impact of childhood diarrhea in the first 2 years of life, examining the cognitive function in children from a Brazilian shanty town [21]. A total of 46 children aged 6-10 years were given five cognitive tests over a period of two years. Early childhood diarrhea was correlated with reduced cognitive function 4-7 years later, as measured by Test of Non-Verbal IntelligenceIII (TONI-III) and WISC-III Digit Span and Coding, and after controlling for maternal education and helminthiasis. The authors concluded the findings have important implications for interventions that may reduce early childhood diarrheal illnesses and their consequences.

Cognitive function has also been assessed in 191 children aged 6-9 years living in an urban slum of Dhaka, Bangladesh

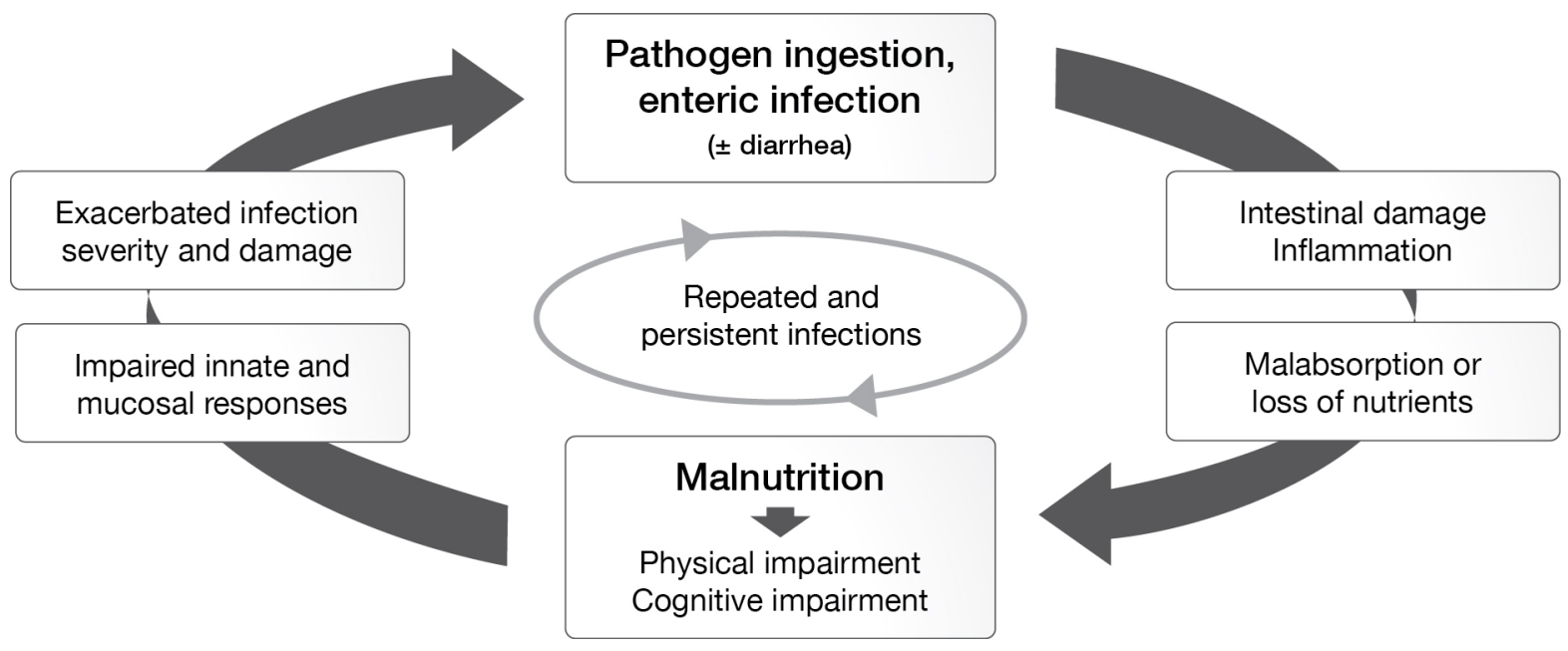

Fig. (1). The cycle of malnutrition and enteric diseases (adapted from [12]). 


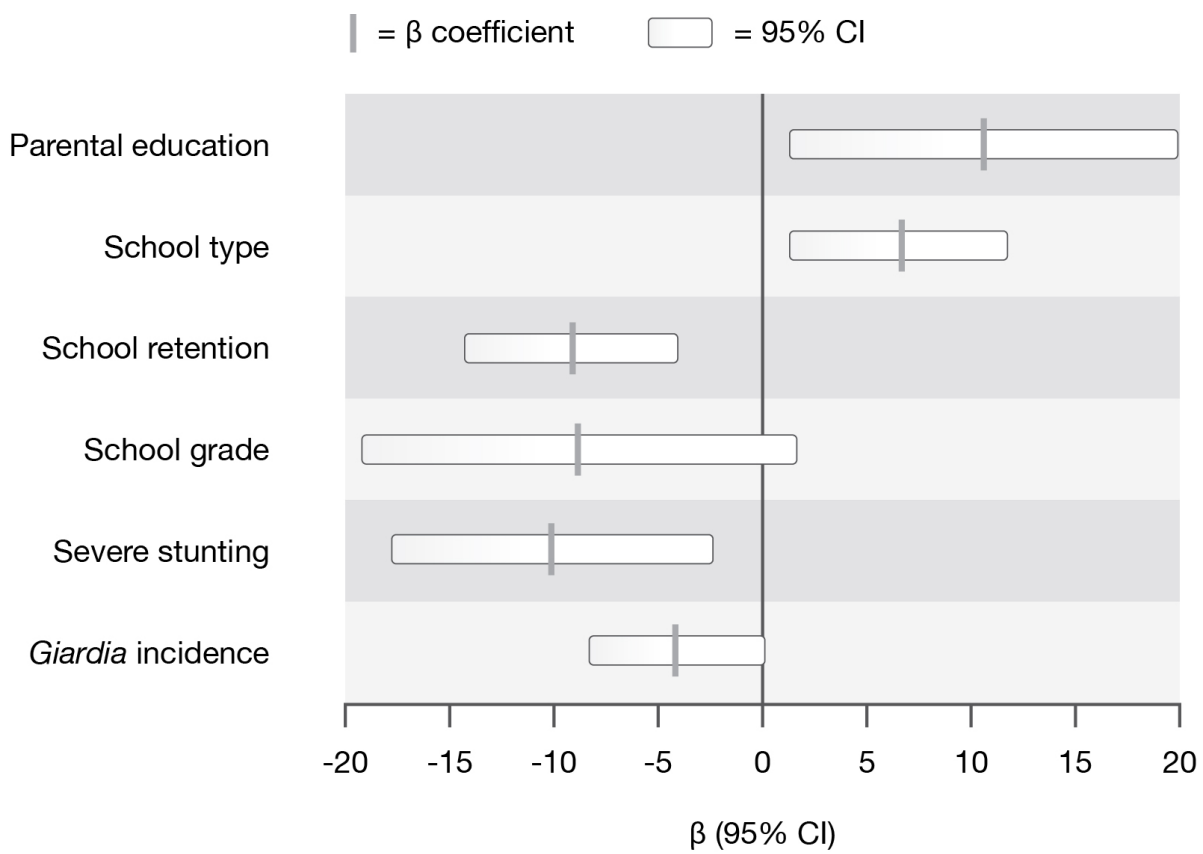

Fig. (2). Impact of malnutrition (indexed by stunting) and Giardia lamblia incidence (more than one episode) on WISC-R test scores [20]. The $\beta$-coefficients fall to the left of the center line (i.e. baseline), indicating negative impacts on WISC-R score; $\mathrm{P}=0.011 v s$ none or not severe stunting and $\mathrm{P}=0.039 v s \leq$ one Giardia lamblia episode, respectively.

[22]. Verbal and non-verbal Wechsler Abbreviated Scale of Intelligence (WASI) test scores were added to a health surveillance database that was compiled over the four previous years. On simple regression analysis, measures of malnutrition, such as baseline height-for-age Z-(HAZ) score, and number of diarrheal episodes were significantly associated with lower scores in the colored progressive matrices (CPM) test. After adjusting for social factors, malnutrition during the school age years was associated with a lower level of cognitive functioning, as was the percent of the study period that intestinal parasites were present.

\section{POTENTIAL MECHANISMS OF ENTERIC PATHOGEN- RELATED IMPAIRMENT OF COGNITIVE DEVE- LOPMENT}

Brain development in the early years is metabolically demanding. The brain of a newborn baby consumes $87 \%$ of the body's metabolic resources, compared with $44 \%$ and $34 \%$ at ages 5 and 10, respectively [23]. Therefore, metabolic resources used for other purposes, such as fighting infections, will compromise the developmental stability of the brain. This premise was tested in a study that correlated the national average intelligence of 113 nations with each nation's infectious disease burden as measured by disabilityadjusted life years lost (DALY) owing to infectious disease [12]. The study provided evidence that infectious disease burden plays a role in the worldwide distribution of cognitive ability, with zero-order correlations between average IQ and parasite stress ranging from $r=-0.76$ to $r=-$ $0.82(\mathrm{p}<0.0001)$.

The hypothesis that the partitioning of metabolic resources plays a key role in mediating the effects of the malnutrition-enteric pathogen vicious cycle is strengthened by studies demonstrating a role for apolipoprotein E4 (ApoE4) in protecting children against the effects of early childhood diarrhea $[24,25]$. ApoE plays a central role in plasma lipoprotein metabolism and in lipid transport within tissues [26] and shows a genetic polymorphism determined by three common alleles, ApoE2, ApoE3 and ApoE4. The ApoE4 allele is postulated to be a 'thrifty gene' based on its conservation in some populations of the developing world and its association with an increased risk of conditions related to 'western' diet and lifestyle, such as coronary artery disease [26]. A study in Egyptian children examined ApoE genotype frequencies and the effects of Giardiasis on the development and cognitive function of children aged 1-9 years [25]. Giardiasis infection was associated with a 10-fold increase in the risk of cognitive impairment and this impairment was significantly higher in Giardiasis-infected non-carriers of ApoE4 compared with carriers of the allele $(p=0.000)[25]$.

In a finding with potentially important significance for aging populations, studies in Brazilian shantytown children indicate that the most affected cognitive impairments in children who experienced heavy burdens of diarrhea is semantic fluency, the same impairment that is most affected in Alzheimer's dementia [27]. The authors conclude that a disruption of semantic fluency associated with diarrhea in the early years of life may increase the vulnerability to neurodegenerative diseases later in life.

\section{INTERRUPTING ENTERIC PATHOGEN TRANS- MISSION THROUGH GOOD HYGIENE PRACTICES}

Enteric pathogens may be transmitted directly (via hand to-hand contact) or indirectly (through contact with food or environmental surfaces). Irrespective of the route of transmission, the human hand acts as one of the most important common denominators in the transmission of enteric pathogens (Fig. 3) [18]. The effectiveness of hand hygiene in controlling infectious diseases is well established. A 2008 meta-analysis of 30 studies showed improvements in hand hygiene reduced gastrointestinal illness by $31 \%(95 \%$ 
confidence intervals [CI] 19\%, 42\%) [28], while a further review showed that hand washing with soap resulted in a $48 \%$ (95\% CI 15\%-71\%) reduction in diarrhea cases in children aged under five [29].

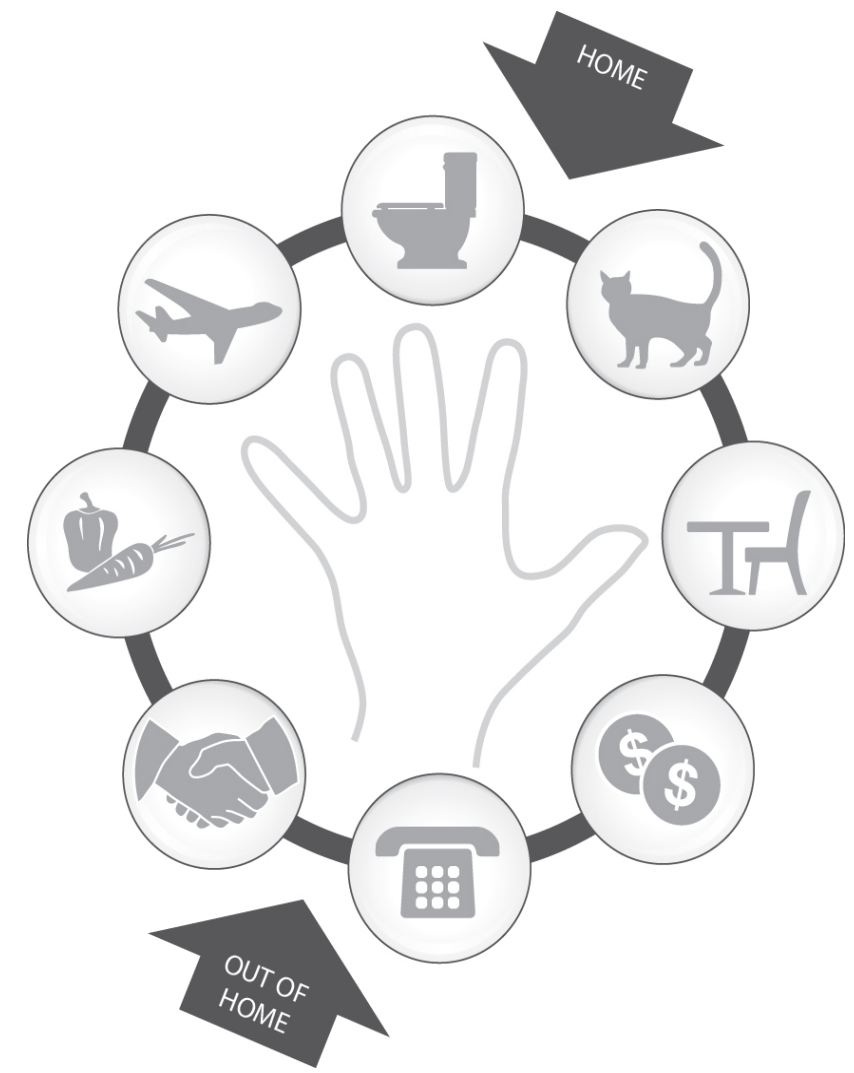

Fig. (3). The human hand is a common denominator in enteric pathogen transmission. Hands can act as conduits to transfer pathogens from surfaces (in the home or out of the home), currency, food, animals (pets or wild), and humans (adapted from [18]).

The 'F-diagram', originally devised by Wagner and Lanois in 1958 (Fig. 4) [30], is a representation of the routes that fecal pathogens take through the environment to reach a new host. All of the transmission routes can be blocked by improved basic hygiene. Hand washing can interrupt pathogen transmission by acting as a primary barrier (removing fecal matter after contact with stools) or as a secondary barrier (before preparing food, handling fluids, feeding and eating) [31]. Good hand hygiene practices - use of water and soap or handwash - can effectively inactivate or remove bacteria, viruses, parasitic ova/(oo)cysts from contaminated hands [32-34]. For example, washing with antibacterial soap has been shown to eliminate more than $99.9 \%$ of Ascaris ova from experimentally-contaminated hands within 30 seconds of contact [35].

The importance of the human hand as a common denominator in enteric pathogen transmission is reflected in guidelines on hand hygiene produced by the World Health Organization [36] and United States Center for Disease Control and Prevention [37].

Hygiene promotion is likely to be most impactful when it targets a few behaviors such as washing hands after defecation and before preparing food. A number of studies have shown substantial reductions in enteric diseases through interventions aimed at improving hand washing. In Burma and Nigeria, a 30\% reduction in diarrheal morbidity was associated with regular hand washing with soap and water [38, 39]. Interestingly, in a meta-analysis of 14 randomized controlled trials, interventions promoting hand washing resulted in a $29 \%$ reduction in diarrhea episodes in institutions in high-income countries (incidence rate ratio [IRR] $0.71,95 \%$ CI 0.60 to $0.84 ; 7$ trials), which was of a similar magnitude to the $31 \%$ reduction in such episodes in communities in low- or middle-income countries (IRR 0.69, $95 \%$ CI 0.55 to $0.87 ; 5$ trials) [38].

Importantly, a study in a high-risk urban squatter settlement of Karachi, Pakistan, demonstrated that the promotion of hand washing in combination with the provision of antibacterial soap measurably improved the hand cleanliness of mothers even when used with contaminated water [40]. In a follow-up study in the same setting, improvement in hand washing with soap and water in the household reduced the incidence of diarrhea among children at high risk of death from diarrhea [41]. Infants living in households that received hand washing promotion and soap had $39 \%$ fewer days with diarrhea $(95 \%$ CI, $-61 \%$ to $-16 \%$ ) versus infants living in control neighborhoods. Severely malnourished children (weight for age z score, <3.0) younger than 5 years living in households that received hand washing promotion and plain soap had $42 \%$ fewer days with diarrhea (95\% CI, $-69 \%$ to $-16 \%$ ) versus severely malnourished children in the control setting.

A recent systematic review found that hand washing with soap, improved water quality, and improved excreta disposal reduced the risk of diarrhea by $48 \%, 17 \%$, and $36 \%$, respectively, in children aged under 5 years [29]. The authors stated that the evidence is "strong enough to support the provision of water supply, sanitation and hygiene for all" [29].

Further to the importance of hand hygiene, according to the International Scientific Forum on Home Hygiene (IFH), there is insufficient awareness of the potential for crosscontamination of pathogens via apparently clean surfaces and apparently clean cloths in the home [42]. IFH guidelines recommend high standards of surface hygiene practices, such as the application of heat or disinfectant use, to achieve satisfactory levels of decontamination [42].

A simple but effective hygiene regimen includes regular hand washing, frequent bathing, and targeted disinfection of surfaces. In fact, a recent study showed that when these practices are routinely followed by families, common infections, including those that affect the gastrointestinal tract, were significantly reduced [43]. This study from South Africa compared hygiene education alone (the control group) with hygiene education plus access to antibacterial soap and surface cleaner [43]. The 922 households involved comprised two groups: one group of housing with indoor taps and flushing toilets (termed 'formal' housing) and one group with communal taps and latrines (termed 'informal' housing). The intervention involved 15 lessons that guided households in building trust and social support, personal skills and group capacity, and personal, home, and environmental hygiene practices. Illness data were gathered for the year following the intervention. The hazard ratios for gastrointestinal illness for the hygiene education group 


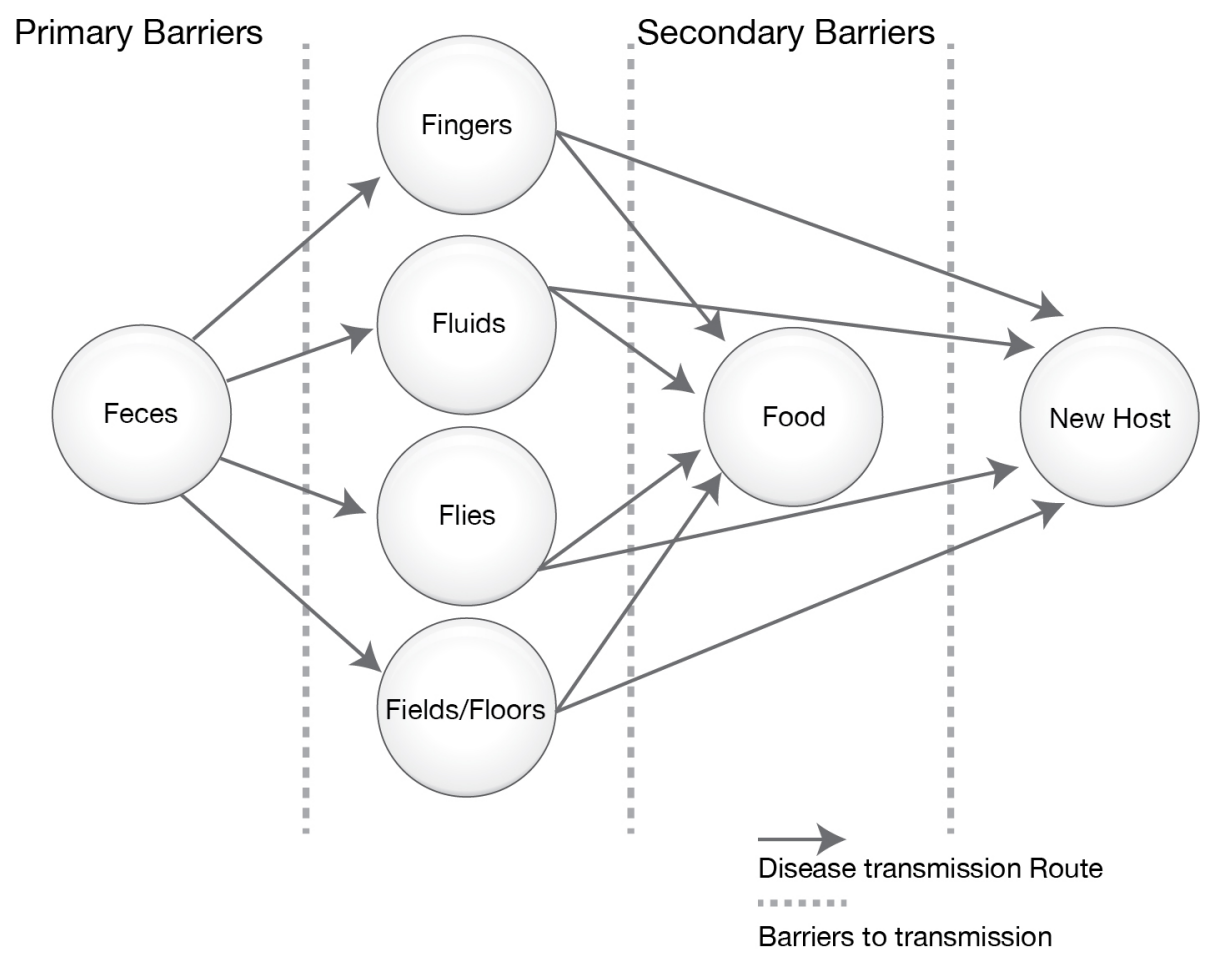

Fig. (4). F-diagram: routes of transmission of infectious diarrheal disease to a new host (adapted from [30]).

compared with the hygiene education plus the use of the antibacterial hygiene products were 1.22 (95\% CI 1.03-1.45) and $1.26(95 \%$ CI $1.05-1.51)$ for the formal and informal housing groups, respectively. The authors concluded that hygiene promotion encompassing both comprehensive participatory hygiene education and the use of personal and home hygiene products (soap and surface cleaner/disinfectant) was an effective and optimal approach to reducing the burden of gastrointestinal illnesses among all household family members.

Importantly, not only does good hygiene has an important role to play in protecting the uninfected, it also has the potential to sustain the long-term benefits of chemotherapy [44]. Indeed, a successful soil-transmitted helminth control program in Korea concluded that improvement of environment and sanitation was of paramount importance for achieving the desired benefits of chemotherapeutic intervention [45].

\section{CONCLUSIONS}

Low levels of access to safe water and safe sanitation continue to drive a high rate of enteric disease in the developing world. Repeated bouts of enteric disease exacerbate malnutrition and lead to a vicious and synergistic cycle of malnutrition-enteric infection-malnutrition [3]. The mitigational role of hygiene practices in the development and/or breaking of this cycle has been proven in a range of interventional studies [43]. Therefore, improved hygiene represents a vital component of any strategy for reducing the burden of enteric infectious disease and may help optimize the chance for every child to reach their full development potential.

\section{CONFLICT OF INTEREST}

The authors declare that they have no competing interests.

\section{ACKNOWLEDGEMENTS}

Both authors contributed extensively to the work presented in thepaper and had responsibility for the final content. The authors would like to thank Mash Health (Teddington, UK) for editorial support in drafting the manuscript. MKI and JRR are engaged in R\&D work at Reckitt Benckiser LLC., Montvale, New Jersey, USA. Medical writing services from Mash Health were funded by Reckitt Benckiser LLC.

\section{REFERENCES}

[1] Irwin LG, Siddiqi A, Hertzman C. Early child development: a powerful equalizer. Final report for the World Health Organization's Commission on the Social Determinants of Health 2007.

[2] Bryce J, Boschi-Pinto C, Shibuya K, Black RE. WHO estimates of the causes of death in children. Lancet 2005; 365: 1147-52.

[3] Guerrant RL, Oria RB, Moore SR, Oria MO, Lima AA Malnutrition as an enteric infectious disease with long-term effects on child development. Nutr Rev 2008; 66: 487-505.

[4] Addy PA, Antepim G, Frimpong EH. Prevalence of pathogenic Escherichia coli and parasites in infants with diarrhoea in Kumasi, Ghana. East Afr Med J 2004; 81: 353-7.

[5] Deen JL, von Seidlein L, Sur D, et al. The high burden of cholera in children: comparison of incidence from endemic areas in Asia and Africa. PLoS Negl Trop Dis 2008; 2: e173.

[6] Harris AM, Chowdhury F, Begum YA, et al. Shifting prevalence of major diarrheal pathogens in patients seeking hospital care during floods in 1998, 2004, and 2007 in Dhaka, Bangladesh. Am J Trop Med Hyg 2008; 79: 708-14. 
[7] Nair GB, Ramamurthy T, Bhattacharya MK, et al. Emerging trends in the etiology of enteric pathogens as evidenced from an active surveillance of hospitalized diarrhoeal patients in Kolkata, India. Gut Pathog 2010; 2: 4.

[8] Sack RB, Siddique AK, Longini IM, et al. A 4-year study of the epidemiology of Vibrio cholerae in four rural areas of Bangladesh. J Infect Dis 2003; 187: 96-101.

[9] Pullan R, Brooker S. The global limits and population at risk of soil-transmitted helminth infections in 2010. Parasit Vectors 2012; 5: 81 .

[10] Moore SR, Lima NL, Soares AM, et al. Prolonged episodes of acute diarrhea reduce growth and increase risk of persistent diarrhea in children. Gastroenterology 2010; 139: 1156-64.

[11] Checkley W, Gilman RH, Epstein LD, et al. Asymptomatic and symptomatic cryptosporidiosis: their acute effect on weight gain in Peruvian children. Am J Epidemiol 1997; 145: 156-63.

[12] Eppig C, Fincher CL, Thornhill R. Parasite prevalence and the worldwide distribution of cognitive ability. Proc Biol Sci 2010; 277: 3801-8

[13] Brooks JT, Ochieng JB, Kumar L, et al. Surveillance for bacterial diarrhea and antimicrobial resistance in rural western Kenya, 19972003. Clin Infect Dis 2006; 43: 393-401.

[14] Ochoa TJ, Ruiz J, Molina M, et al. High frequency of antimicrobial drug resistance of diarrheagenic Escherichia coli in infants in Peru. Am J Trop Med Hyg 2009; 81: 296-301.

[15] Roychowdhury A, Pan A, Dutta D, et al. Emergence of tetracycline-resistant Vibrio cholerae $\mathrm{O} 1$ serotype Inaba, in Kolkata, India. Jpn J Infect Dis 2008; 61: 128-9.

[16] Nataro JP, Steiner T, Guerrant RL. Enteroaggregative Escherichia coli. Emerg Infect Dis 1998; 4: 251-61.

[17] Rajendran P, Ajjampur SS, Chidambaram D, et al. Pathotypes of diarrheagenic Escherichia coli in children attending a tertiary care hospital in South India. Diagn Microbiol Infect Dis 2010; 68: 11722.

[18] Alum A, Rubino JR, Ijaz MK. The global war against intestinal parasites - should we use a holistic approach? Int J Infect Dis 2010; 14: e732-8.

[19] Paul I, Gnanamani G. Re-infection estimation of soil-transmitted helminths among slum school children in Visakhapatnam, Andhra Pradesh. J Commun Dis 1998; 30: 245-9.

[20] Berkman DS, Lescano AG, Gilman RH, Lopez SL, Black MM. Effects of stunting, diarrhoeal disease, and parasitic infection during infancy on cognition in late childhood: a follow-up study. Lancet 2002; 359: 564-71.

[21] Niehaus MD, Moore SR, Patrick PD, et al. Early childhood diarrhea is associated with diminished cognitive function 4 to 7 years later in children in a northeast Brazilian shantytown. Am J Trop Med Hyg 2002; 66: 590-3.

[22] Tarleton JL, Haque R, Mondal D, Shu J, et al. Cognitive effects of diarrhea, malnutrition, and Entamoeba histolytica infection on school age children in Dhaka, Bangladesh. Am J Trop Med Hyg 2006; 74: 475-81.

[23] Holliday, M. A. Body composition and energy needs during growth. In: Falkner F, Tanner JM, Eds. Human growth: a comprehensive treatise. New York, NY: Plenum 1986; vol. 2: pp. 101-17.

[24] Oria RB, Patrick PD, Blackman JA, Lima AA, Guerrant RL. Role of apolipoprotein E4 in protecting children against early childhood diarrhea outcomes and implications for later development. Med Hypotheses 2007; 68: 1099-107.

[25] Yahya RS, Awad SI, El-Gayar EK, Elborii H, Ragab A, Al-Sawah GA. Apolipoprotein E4 effect on development and cognitive function in giardia-infected children. Parasitologists United Journal 2009; 2: 111-8.

[26] Corbo RM, Scacchi R. Apolipoprotein E (APOE) allele distribution in the world. Is APOE*4 a 'thrifty' allele? Ann Hum Genet 1999 63: 301-10.

[27] Oria RB, Costa CM, Lima AA, Patrick PD, Guerrant RL. Semantic fluency: a sensitive marker for cognitive impairment in children with heavy diarrhea burdens? Med Hypotheses 2009; 73: 682-6.

[28] Aiello AE, Coulborn RM, Perez V, Larson EL. Effect of hand hygiene on infectious disease risk in the community setting: a meta-analysis. Am J Public Health 2008; 98: 1372-81.

[29] Cairncross S, Hunt C, Boisson S, et al. Water, sanitation and hygiene for the prevention of diarrhoea. Int J Epidemiol 2010; 39: i193-205.

[30] Wagner EG, Lanoix JN. Excreta Disposal for Rural Areas and Small Communities. Geneva. World Health Organization Monograph series No 39 WHO 1958.

[31] Curtis V, Cairncross S, Yonli R. Domestic hygiene and diarrhoea pinpointing the problem. Trop Med Int Health 2000; 5: 22-32.

[32] Fung IC, Cairncross S. Ascariasis and handwashing. Trans R Soc Trop Med Hyg 2009; 103: 215-22.

[33] Han AM, Hlaing T, Kyin ML, Saw T. Hand washing intervention to reduce ascariasis in children. Trans R Soc Trop Med Hyg 1988; 82: 153 .

[34] Liu P, Yuen Y, Hsiao HM, Jaykus LA, Moe C. Effectiveness of liquid soap and hand sanitizer against Norwalk virus on contaminated hands. Appl Environ Microbiol 2010; 76: 394-9.

[35] Reckitt Benckiser. Clinical Study Report M5013-003-v1.0. 2009.

[36] National Comprehensive Cancer Network. Clinical Practice Guidelines in Oncology: Chronic Myelogenous Leukemia, V.2.2011. Available at http://www.nccn.org/professionals/physici an gls/PDF/cml.pdf (accessed May 2012).

[37] Centers for Disease Control and Prevention. Guideline for Hand Hygiene in Health-Care Settings Recommendations of the Healthcare Infection Control Practices Advisory Committee and the HICPAC/SHEA/APIC/IDSA Hand Hygiene Task Force. MMWR 2002; 51: 1-45.

[38] Ejemot RI, Ehiri JE, Meremikwu MM, Critchley JACochrane Database Syst Rev. 2008(1): CD004265.

[39] Han AM, Ave T, Hlaing T. An outbreak of dysentery due to Shigella dysenteriae type 1 in Rangoon, Burma. J Diarrhoeal Dis Res 1987; 5: 30-5.

[40] Luby SP, Agboatwalla M, Raza A, et al. Microbiologic effectiveness of hand washing with soap in an urban squatter settlement, Karachi, Pakistan. Epidemiol Infect 2001; 127: 237-44.

[41] Luby SP, Agboatwalla M, Painter J, Altaf A, Billhimer WL, Hoekstra RM. Effect of intensive handwashing promotion on childhood diarrhea in high-risk communities in Pakistan: a randomized controlled trial. JAMA 2004; 291: 2547-54.

[42] International Scientific Forum on Home Hygiene. Guidelines for prevention of infection and cross-infection in the domestic environment 2002.

[43] Cole E, Hawkley M, Rubino J, et al. Comprehensive community hygiene promotion in peri-urban Cape Town: gastrointestinal \& respiratory disease reduction in families. Poster presented at the 14th International Congress on Infectious Diseases; 9-12 March 2010; Miami, Florida, USA.

[44] Asaolu SO, Ofoezie IE. The role of health education and sanitation in the control of helminth infections. Acta Trop 2003; 86: 283-94.

[45] Hong ST, Chai JY, Choi MH, Huh S, Rim HJ, Lee SH. A successful experience of soil-transmitted helminth control in the Republic of Korea. Korean J Parasitol 2006; 44: 177-85.

This is an open access article licensed under the terms of the Creative Commons Attribution Non-Commercial License (http: //creativecommons.org/licenses/by$\mathrm{nc} / 3.0 /$ ) which permits unrestricted, non-commercial use, distribution and reproduction in any medium, provided the work is properly cited. 